\section{Accelerator \& Fusion Research Division}

Presented at the National Conference on Synchrotron Radiation Instrumentation, Argonne, $\mathbb{L}$, October 17-20, 1995, and to be published in the Proceedings

Installation of the MAXIMUM Microscope at the ALS

W. Ng, R.C.C. Perera, and J.H. Underwood

October 1995

\section{RECEIVED \\ JAII 24 194\$ \\ $\boldsymbol{Q} \mathbf{S} T_{1}$}

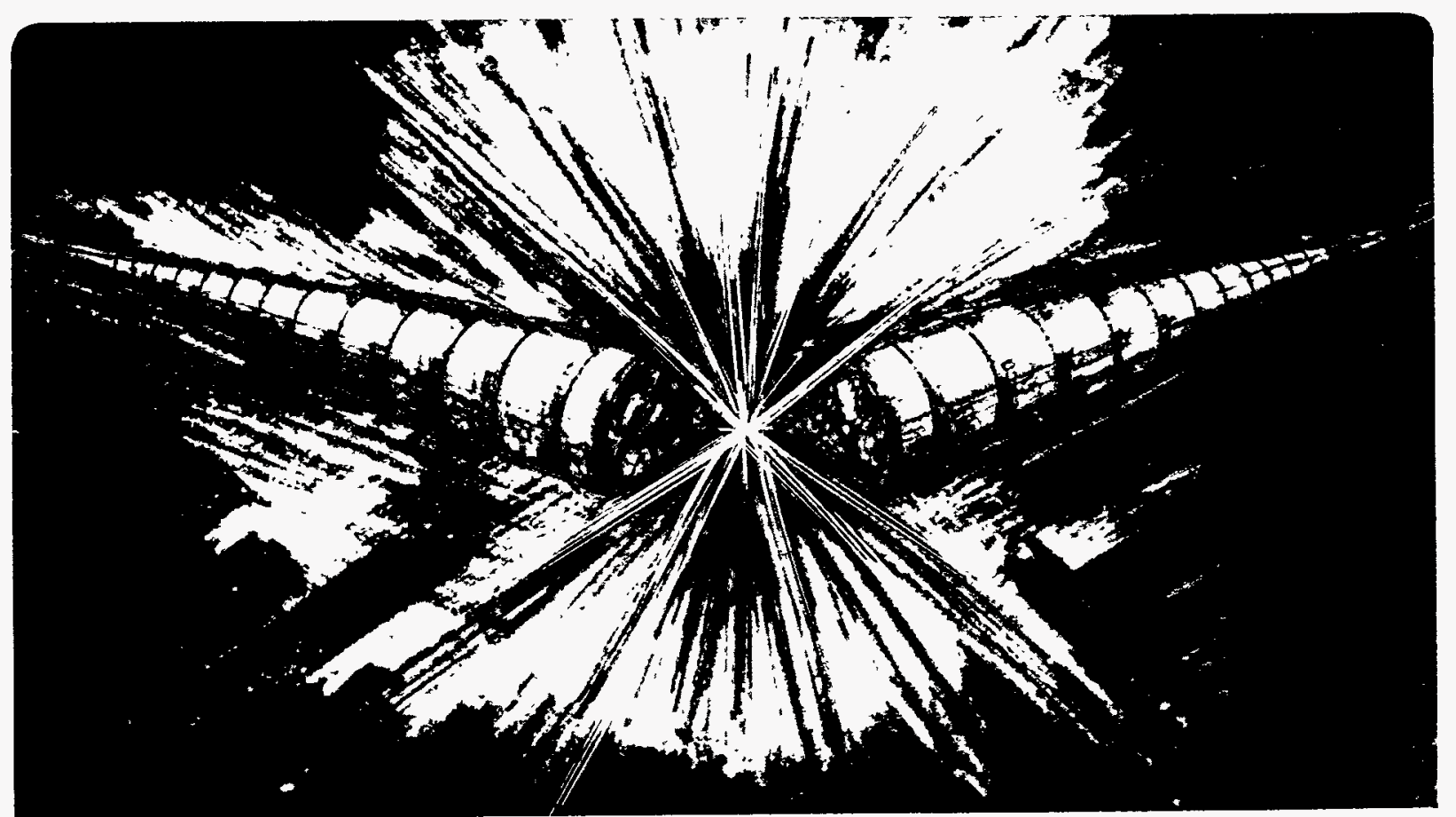

Prepared for the U.S. Department of Energy under Contract Number DE-AC03-76SF00098 DISTRIDUTIOA OF THE UOUUAEIT IS LALETEO 


\section{DISCLAIMER}

This document was prepared as an account of work sponsored by the United States Government. While this document is believed to contain correct information, neither the United States Government nor any agency thereof, nor The Regents of the University of California, nor any of their employees, makes any warranty, express or implied, or assumes any legal responsibility for the accuracy, completeness, or usefulness of any information, apparatus, product, or process disclosed, or represents that its use would not infringe privately owned rights. Reference herein to any specific commercial product, process, or service by its trade name, trademark, manufacturer, or otherwise, does not necessarily constitute or imply its endorsement, recommendation, or favoring by the United States Government or any agency thereof, or The Regents of the University of Califomia. The views and opinions of authors expressed herein do not necessarily state or reflect those of the United States Government or any agency theteof, or The Regents of the University of Califomia.

Lawrence Berkelcy National Laboratory

is an equal opportunity employer. 


\title{
INSTALLATION OF THE MAXIMUM MICROSCOPE AT THE ALS*
}

\author{
W. Ng, R.C.C. Perera, J.H. Underwood
}

\author{
Advanced Light Source \\ Accelerator and Fusion Research Division \\ Lawrence Berkeley National Laboratory \\ Berkeley, CA 94720, USA \\ Center for X-ray Optics \\ Materials Sciences Division \\ Lawrence Berkeley National Laboratory \\ Berkeley, CA 94720, USA
}

Submitted to the National Conference on Synchrotron Radiation Instrumentation, Argonne, IL, October 1995

*This work was supported by the Director, Office of Energy Research, Office of Basic Energy Sciences, Materials Sciences Division, of the U.S. Department of Energy, under Contract No. DE-AC03-76SF00098. 
$\because$
$\because \cdots$

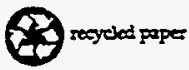




\title{
Installation of the MAXIMUM Microscope at the ALS
}

\author{
W. Ng, R.C.C. Perera, J.H. Underwood \\ Lawrence Berkeley National Laboratory, Berkeley, CA 94720 \\ S. Singh, H. Solak, and F. Cerrina \\ Center for X-ray Lithography, University of Wisconsin - Madison \\ Stoughton, WI, 53589
}

\begin{abstract}
The MAXIMUM scanning X-ray microscope, developed at the Synchrotron Radiation Center (SRC) at the University of Wisconsin - Madison was implemented on the Advanced Light Source in August of 1995. The microscope's initial operation at SRC successfully demonstrated the use of multilayer coated Schwarzschild objective for focusing $130 \mathrm{eV} x$-rays to a spot size of better than 0.1 micron with an electron energy resolution of $250 \mathrm{meV}$. The performance of the microscope was severely limited, because of the relatively low brightness of SRC, which limits the available flux at the focus of the microscope. The high brightness of the ALS is expected to increase the usable flux at the sample by a factor of 1000 . We will report on the installation of the microscope on bending magnet beamline 6.3 .2 at the ALS and the initial measurement of optical performance on the new source, and preliminary experiments with surface chemistry of $\mathrm{HF}$ etched Si will be described.
\end{abstract}

\section{Introduction}

The photoemission microscope MAXIMUM was designed and built by the University of Wisconsin and it was installed at the Synchrotron Radiation Center[1]. The instrument was developed in three phases, which started in 1988 and spanned a period of 6 years. We have successfully demonstrated the use of reflective optics for focusing soft-X-rays near $100 \mathrm{eV}$ to a spot size of $95 \mathrm{~nm}$, and we also show the possibility of spectromicroscopy at this resolution with high energy resolution. Over the last 2 years, the microscope was used to study a range of surface physics problems of both fundamental and applied interests[2,3,4]. During the operation of the microscope, it became apparent that the microscope's performance is severely hampered by the relatively low brightness of Aladdin, which limits the available flux at the microscope's focus, and 
this in turn limits the achievable spatial resolution because of signal-to-noise considerations. The MAXIMUM experiments performed at SRC were often forced to operate at a reduced resolution, in order to achieved realistic counting rates. The development of third generation light sources like the Advance Light Source (ALS) and Elettra (Trieste) with their increased brightness has provided the possibility of tremendous improvement in achievable resolution. A Participating Research Team (PRT) was formed to move MAXIMUM from Wisconsin for installation and operation at ALS. The microscope was moved to the ALS in April of 1995. It was installed on bend.magnet beamline 6.3.2 and preliminary tests and experiments were performed at the ALS. We will discuss the installation and characterization of the microscope, and we will report on the first results from this test experiment. We will also discuss plans for moving to an undulator source and the expected performance.

\subsection{Microscope Design}

The detailed design and implementation of the microscope have been published previously[1], and it will be briefly reviewed here. The basic layout of the microscope is as follows: radiation from the synchrotron source is monochromatized and focused to illuminate a pinhole, which serves as the source for the microscope optics. A multilayer-coated Schwarzschild Objective (S.O.) produces an image of the pinhole with a $20 \mathrm{X}$ demagnification. When a sample is placed at the focus, photoelectrons emitted from the irradiation are collected by an electron spectrometer. Information regarding the band structure of the irradiated area can be obtained from the Energy Distribution Curves (EDC). The sample is rastered to produce a 2-D image, and by using different parts of the EDC as the input signal, different contrast mechanisms can be produced. One of the most important strength of photoemission microscopy is the large number of well-understood contrast mechanisms that can be used for imaging. The contrast mechanisms that we have explored are: a) Topography, b) Elemental distribution, c) Chemical shifts, d) Band bending and Fermi level, and e) Valence band lineup. f) Electrostatics. 
The installation of MAXIMUM at the ALS will have two phases. We first moved the existing microscope, the electron energy analyzer and the sample preparation chamber (a fully integrated system) to the ALS for installation on BL 6.3.2. In the second phase, the microscope will be installed on undulator beamline BL 12.0, and we will also extend the performances of the microscope by ungrading the existing optics and the electron energy analyzer. The spatial resolution is expected to reach below $500 \AA$ with high count rate. We will report on the progress of the first phase of the installation.

\section{Installation at BL 6.3.2 at the ALS}

MAXIMUM was disassembled and shipped from SRC in May of 1995 . Modification to the support structures was necessary due to seismic requirements at ALS. The upgrade involved the replacement of the old kinematicly mounted support by a standard six struts support system. The sample transfer system was also rebuilt with a six struts support system. The upgrade was completed in August of 1995. The microscope was installed on BL 6.3.2 at the ALS for preliminary testing. BL 6.3.2 is a bending magnet beamline, operating in the range of $50-1000 \mathrm{eV}$. This beamline was designed to be used principally for calibration and characterization of $x$-ray optical components at the ALS. The bend magnet source and the beamline's optical characteristic did not fill the pinhole and the microscope's objective effectively. Nevertheless, it was adequate for preliminary testing of the microscope. The main objective of this experimental run was to characterize the reassembled microscope with its new support stand and sample transfer system. Preliminary experiments were also carried out at a photon energy of $129.3 \mathrm{eV}$ to test and characterize the performance of MAXTMUM at ALS Beamline 6.3.2. The measured flux at the microscope focus was $2 \times 10^{8} \mathrm{phs} / \mathrm{sec}$. The measured flux was 50X less than expected; this discrepancy was caused by the large figure errors in the final refocussing mirror of the bemline, which produced multiple vertical images at the pinhole. For these preliminary experiments, we chose a pinhole which operates at a modest spatial resolution of $1.25 \mu \mathrm{m}$. After the microscope was characterized, we used MAXIMUM's ability to image local differences in surface chemistry of a sample, in this case a $\mathrm{Si}$ wafer patterned with $92 \mathrm{~nm}$ thick silicon 
nitride features ${ }^{1}$. This experiment is part of an ongoing project with the microscope. Fig. 1 shows a partial yield image of the sample. The image is $80 \mu \mathrm{m} \times 80 \mu \mathrm{m}$ and it was acquired with a step size of $1 \mu \mathrm{m}$ at a photoelectron energy of $0 \mathrm{eV}$. The bright raised square corresponds to the nitride feature and the surrounding area corresponds to the silicon substrate. EDCs taken on $\mathrm{Si}$ and SiNH regions of the sample show a dramatic chemical difference. These are shown in Fig.2 and Fig. 3, respectively. The sample was subjected to a light chemical cleaning by immersion in $1 \% \mathrm{HF}$ for $4 \mathrm{~min}$. followed by a $2 \mathrm{~min}$. rinse with deionized $\mathrm{H}_{2} \mathrm{O}$. It was then put into the experimental chamber and pumped down within 15 minutes. When a pressure of $1 \times 10^{-7}$ torr was reached (after 1 hour), the focused $x$-ray spot was positioned at the corner of a SiNH feature on the Si substrate. A cylindrical mirror analyzer (CMA) with a workfunction of $5 \mathrm{eV}$ was used to acquire EDC's at both locations. An EDC acquired on the Si region is shown in Fig. 2 after background removal and curve fitting with Gaussian functions. Gaussian functions were used since instrumental broadening is expected to dominate in our spectra. Fig.3 shows the EDC taken on the SiNH region. In both EDC's Peak A corresponds to the $2 p$ core level of $S i$. The $2 p_{3 / 2}$ and $2 p_{1 / 2}$ components were not resolved; due to the modest energy resolution chosen, the peak is found to be centered between the two at a kinetic energy of $24.8 \mathrm{eV}$ (binding energy $99.5 \mathrm{eV}$ ). Fig.2 shows that two other peaks, $B_{1}$ at $22.0 \mathrm{eV}$ and $\mathrm{C}$ at $21.1 \mathrm{eV}$, are found in addition to $\mathrm{A}_{1}$ on the chemically cleaned $\mathrm{Si}$. Notwithstanding the noise in the data and the difficulty in obtaining a perfect fit, these peaks can be assigned, tentatively, to the $\mathrm{Si}^{+3}$ and $\mathrm{Si}^{+4}$ oxidation states of $\mathrm{Si}$, since $0.8 \mathrm{eV}-0.9 \mathrm{eV}$ of chemical shift can be attributed to each bond a $\mathrm{Si}$ atom has with an oxygen atom, with the shift for $\mathrm{SiO}_{2}$ ranging from $3.6 \mathrm{eV}$ to $4.4 \mathrm{eV}[5]$. The $\mathrm{SiO}_{2}$ peak is also broadened as expected. The intensity of the clean $\mathrm{Si}$ is lower than that of the oxide peaks since the chemical clean was not sufficiently thorough. It is well known that the oxidation of HF etched Si not only proceeds more slowly than that of annealed Si but also results in the preferential formation of the lower oxidation state oxides $\mathrm{SiO}_{2}, \mathrm{SiO}$, and $\mathrm{Si}_{2} \mathrm{O}_{3}$ over $\mathrm{SiO}_{2}[6,7]$. The lower oxidation state oxides form first also on annealed Si[8]. This is consistent with the lowered rate of oxidation of HF-cleaned Si. The presence of $\mathrm{SiO}_{2}$ on our sample can partially be explained by the incomplete removal of the native oxide present on the

\footnotetext{
${ }^{1}$ Stoichiometrically, silicon nitride can be represented by $\mathrm{Si}_{3} \mathrm{~N}_{4}$. However, the silicon nitride formed in practice does not conform to this formulation. The nitride is often also in a hydrogenated state, regardless of the method of formation. In this paper the expression SiNH will be used to refer to silicon nitride
} 
Si wafer by the light HF etch used. A stronger HF etch for 20-30 minutes would have been more effective. Cleaner equipment and purer solutions are also essential in avoiding contamination of the wafer during cleaning[9]. However, the fact that the $\mathrm{SiO}_{2}$ chemical shift is at the lower end of the range at $-3.6 \mathrm{eV}$ rather than the $-4.0 \mathrm{eV}$ typical of the native oxide, may indicate that strain at the $\mathrm{Si} / \mathrm{SiO}_{2}$ interface may be lowering Si-O bonding energies[7,10]. In this case, incomplete removal of the native oxide is not implicated. Fig. 3 shows the two shifted peaks $B_{2}$ and $D$ in addition to the clean Si peak $A_{2}$ on the EDC taken on the SiNH feature. Peak D at $19.3 \mathrm{eV}$ is not present in the EDC acquired on the Si substrate and has been observed on SiNH in past experiments on SiNH as well. It can be assigned to SiNH although the nominal chemical shift for stoichiometric SiNH is only $2.7 \mathrm{eV}[5]$ because of local charging of the almost $0.1 \mu \mathrm{m}$ thick nitride layer and the fact that the exact chemical composition of the SiNH in this sample is not known. Peak $\mathrm{B}_{2}$ at $21.7 \mathrm{eV}$ may arise from $\mathrm{Si}_{2} \mathrm{O}_{3}$, although its chemical shift of $-3.0 \mathrm{eV}$ is $0.2 \mathrm{eV}$ off the expected shift of $\mathrm{Si}_{2} \mathrm{O}_{3}$ on $\mathrm{Si}$. This oxide of silicon may have resulted from a contamination layer formed on the surface of the SiNH during ion-implantation of the sample after nitride patterning which was not completely removed during the chemical cleaning, which is designed for $\mathrm{Si}$, not SiNH. Another evidence that this is indeed the case is that Peak $B_{2}$ was not present on SiNH in an experiment on an identical sample cleaned by heating to $1200^{\circ} \mathrm{C}$ in UHV, which results in the removal of material from the entire surface of the sample. In the current experiment, both peaks are widened as expected for chemically shifted components. The fraction of signal from clean $\mathrm{Si}$ is expectedly lower for a $\mathrm{SiNH}$ sample, but the fraction of SiNH signal is lower than that of the silicon oxide, because of the incomplete chemical clean.

\section{Discussions}

The first test of the MAXIMUM microscope at the ALS was successful. The performance of the microscope was close to the expected level for a bending magnet beamline. We expect to enjoy the improved signal very soon at the ALS, when the mirrors in the refocussing mirror box of BL6.3.2 are replaced with lower figure error mirrors and the flux previously lost to the multiple vertical images is regained. The full potential of the MAXIMUM microscope operating at close to the diffraction limit will be realized when it is moved to the undulator beamline BL 12.0. The preliminary experiments on chemical 
etching of the Si/SiNH system demonstrated the feasibility of such experiments. Clearly, more detailed studies need to be done to better understand and resolve some of the issues in this complex system. HF etched Si is a very important system for technological applications in the IC industry and exhibits interesting physics as well. We plan further higher resolution experiments on various chemically cleaned H-terminated samples. With improved sample preparation, we expect to conduct spectromicroscopy of stable, nominally unpinned $\mathrm{Si}(100)$ and (111) with core level spectra containing varying ratios of surface shifted components to study local variations in the surface chemistry of chemically cleaned $\mathrm{Si}$.

\section{Acknowledgments}

This work was funded by NSF under grants DMR-87-13455 and DMR-89-19297 for the construction of the microscope and by the department of Energy. Support also came from the Center for X-ray Optics and Xerox Corporation. I would like to thank, A.K. Ray-Chaudhuri, T. Liang, J. Wallace, J. Welnak, C. Capasso and G. Margaritondo for their part in the original construction and operation of the microscope. I would also like to thank H. Padmore, T. Lauritzen and P. McKean and N. Kellogg for their support at the ALS. We would also like to thank J. Kortright and N. Newman of LBNL for their help. 


\section{References}

1) W. Ng, A.K. Ray-Chaudhuri, S. Liang, S. Singh, H. Solak, J. Welnak, F. Cerrina, G. Margaritondo J.H. Underwood ,J.B. Kortright and R.C.C. Perera, Nucl. Instr. and Meth., A347, 422, (1994).

2) W. Ng, A.K. Ray-Chaudhuri, S. Liang, J. Welnak, J. Wallace, S. Singh, C. Capasso, F. Cerrina, G. Margaritondo, J.H. Underwood, J.B. Kortright, R.C.C. Perera, SPIE Proc. 1741, 296 (1992).

3) A.K. Ray-Chaudhuri, W. Ng, S. Liang, S. Singh, J. Weinak, J. Wallace, C. Capasso, F. Cerrina, G. Margaritondo, J.H. Underwood, J.B. Kortright, R.C.C. Perera, J. Vac. Sci. Technol. A, 10, 2324, (1993).

4) F. Cerrina, A.K. Ray-Chaudhuri, W. Ng, S. Liang, S. Singh, J. Welnak, J. Wallace, C.Capasso, J.H. Underwood, J.B. Kortright, R.C.C. Perera, G. Margaritondo, Appl. Phys. Lett. 63, 63 (1993).

5) B. Lai Ph.D thesis, Photoemission Study of Synchrotron Radiation Stimulated Formation of Silicon Nitride, University of Wisconsin - Madison, 1988

6) M. Nakazawa, Y. Nishioka, H. Sekiyama and S. Kawase, J. Appl. Phys., 65, 4019, (1989).

7) J.M.C. Thornton and R.H. Williams, Physica Scripta, 41, 1047, (1990).

8) F.J. Himpsel, F.R. McFeely, A. Taleb-Ibrahimi, J.A. Yarmoff and G. Hollinger, Phys. Rev. B, 38, 6084, (1988).

9) T. Takahagi, I. Nagai, A. Ishitani and H. Kuroda, J. Appl. Phys., 64, 3516, (1988).

10) A. Namiki, K. Tanimoto, T. Nakamura, N. Ohtake and T. Suzaki, Surface Science, 222, 530, (1989).

\section{Figure Captions}

Fig. 1 Secondary electron $80 \mu \mathrm{m} \times 80 \mu \mathrm{m}$ image of a pad of SiNH on Si. The raised square is a SiNH feature and the surrounding area is the Si substrate.

Fig. 2 EDC of the Si $2 p$ acquired on the Si area of the sample depicted above. The peaks $A_{1}, B_{1}$, and $C$ correspond, respectively, to clean $\mathrm{Si}, \mathrm{Si}_{2} \mathrm{O}_{3}$, and $\mathrm{SiO} 2$.

Fig. 3 EDC of the Si $2 p$ acquired on the SiNH feature on the sample depicted above. Peaks $A_{2}, B_{2}$, and D are assigned to clean $\mathrm{Si}_{1} \mathrm{Si}_{2} \mathrm{O}_{3}$ (tentatively), and $\mathrm{SiNH}$, respectively. 


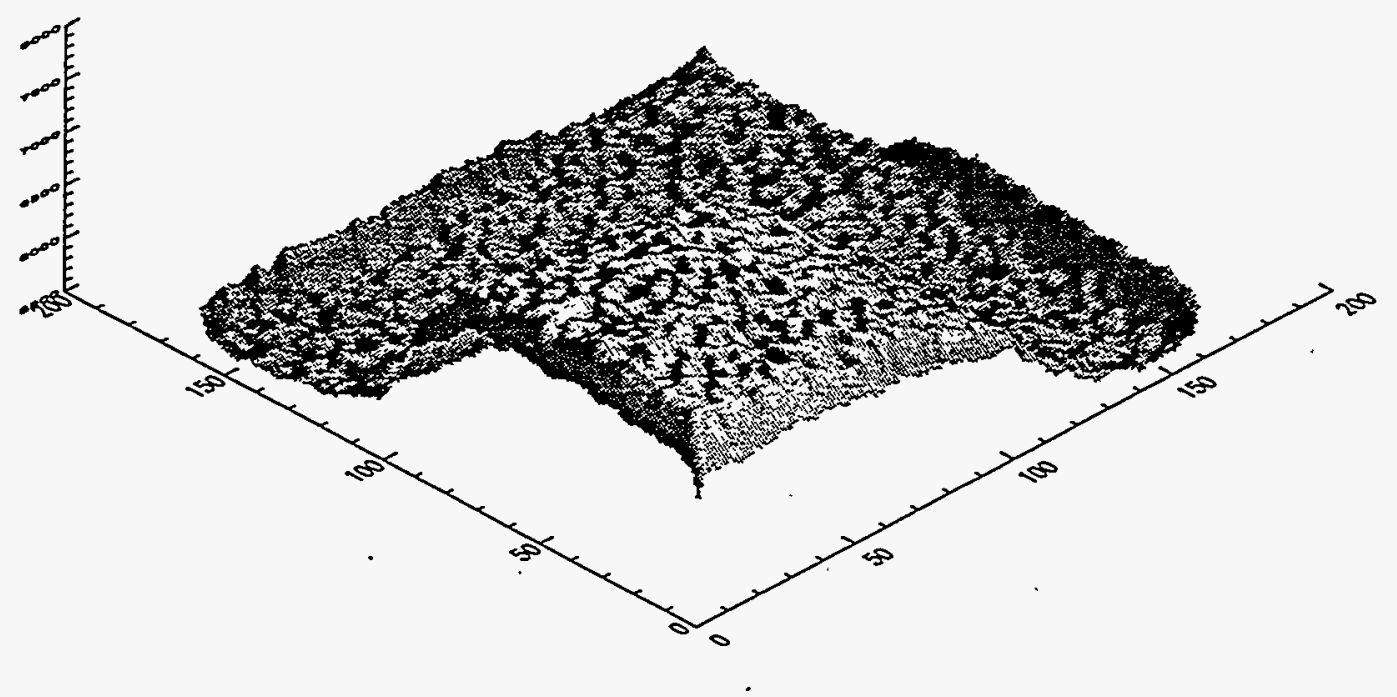

Fig.1 


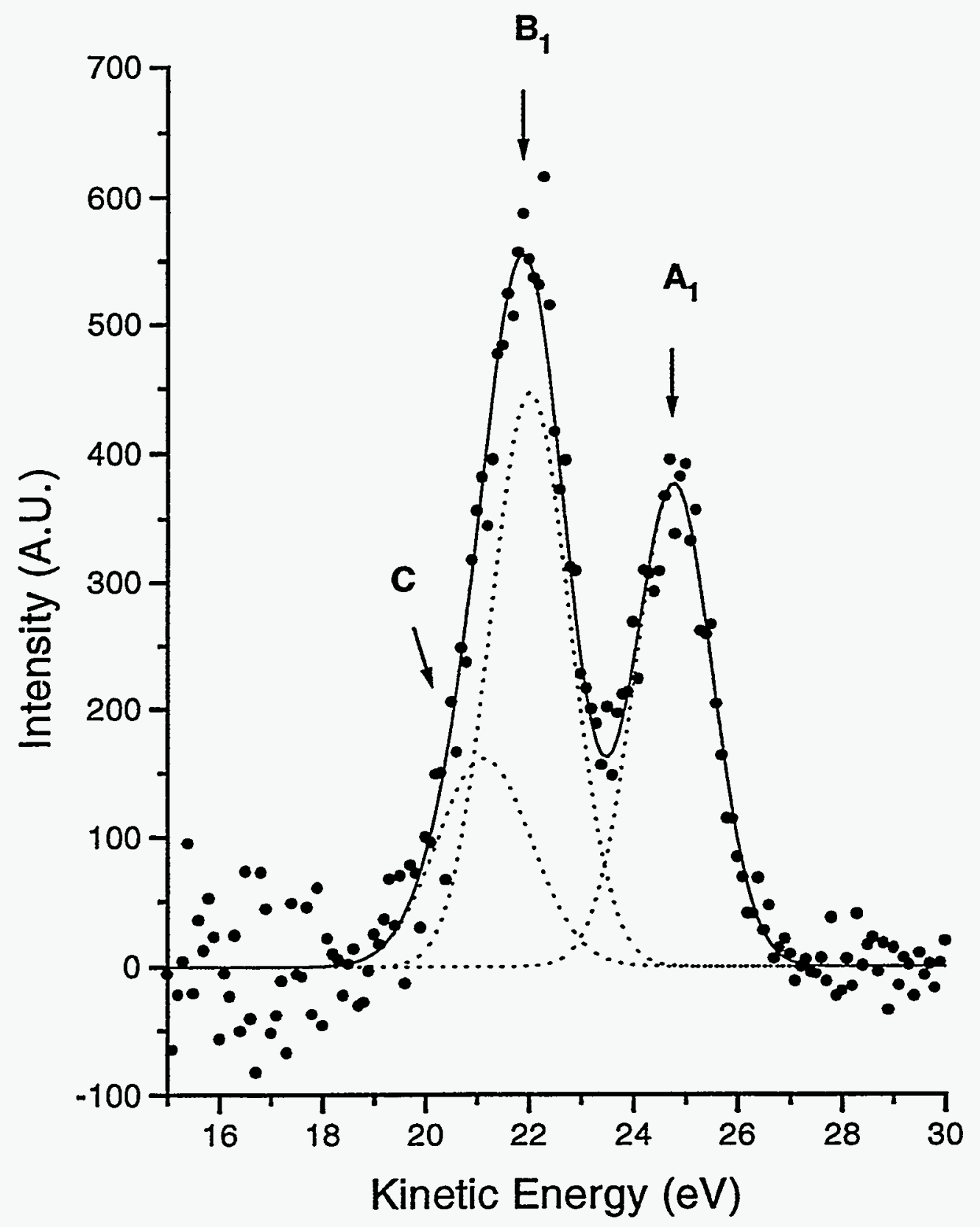

Fig.2 


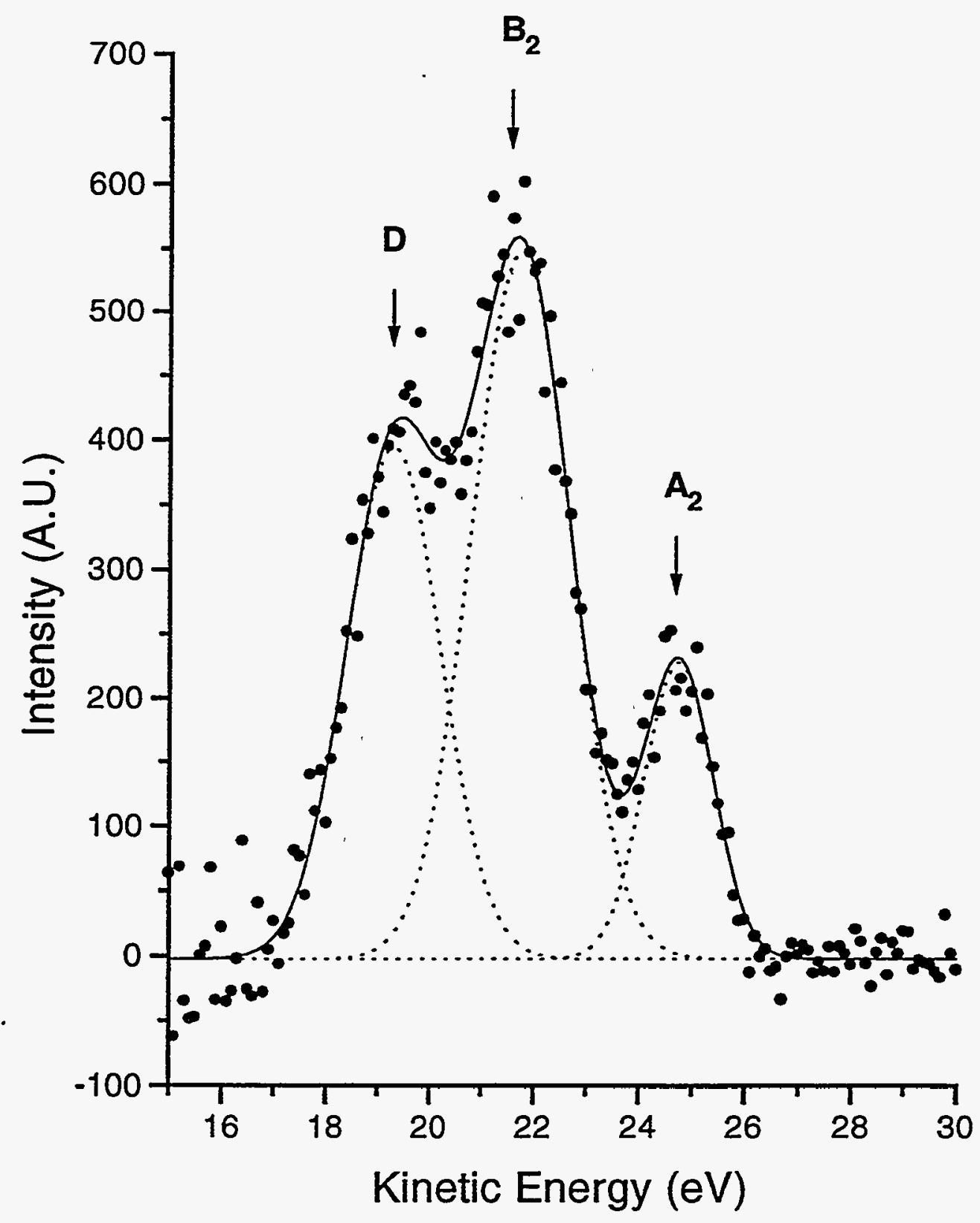

Fig.3 
LAWRENCE BERKELEY NATIONAL LABORATORY

UNIVERSITY OF CALIFORNIA

TECHNICAL \& ELECTRONIC INFORMATION DEPARTMENT

BERKELEY, CALIFORNIA 94720 
